\title{
Two Primary Teachers Developing their Teaching Problem-solving during Three-year In-service Training
}

\author{
Päivi Maria Portaankorva-Koivisto ${ }^{1 *}$ (D) , Anu Tuulikki Laine ${ }^{1}$ (D) Maija Ahtee $^{1}$ (D)
}

\author{
${ }^{1}$ University of Helsinki, FINLAND \\ *Corresponding Author: paivi.portaankorva-koivisto@helsinki.fi
}

Citation: Portaankorva-Koivisto, P. M., Laine, A., Ahtee, M. (2021). Two Primary Teachers Developing their Teaching Problem-solving during Three-year In-service Training. International Electronic Journal of Mathematics Education, 16(1), em0624. https://doi.org/10.29333/iejme/9617

\begin{tabular}{|c|c|}
\hline ARTICLE INFO & ABSTRACT \\
\hline Received: 2 Jun. 2020 & The use of open problem-solving tasks in mathematics education challenges teachers' beliefs, knowledge and \\
\hline Accepted: 22 Oct. 2020 & $\begin{array}{l}\text { practices. This article examines the practices of two primary teachers and their } 3 \text { rd to } 5 \text { th grade classes during a } \\
\text { three-year in-service teacher training project aiming to increase mathematical problem-solving in class. Three } \\
\text { lesson videos and two interviews with each teacher were used to provide the data for this study. The results show } \\
\text { how different teachers in terms of their beliefs, knowledge and practices during the problem-solving activities can } \\
\text { produce mathematically different learning opportunities. Teacher Ann saw mathematics as too rigorous, and to } \\
\text { combat this, gave her pupils a great deal of autonomy. Her pupils were encouraged to come up with creative } \\
\text { solutions. Teacher Beate emphasized mathematical understanding. Her pupils were guided cognitively and they } \\
\text { came up with mathematically elegant solutions. In teaching open problem-solving both autonomy and cognitive } \\
\text { guidance are needed. }\end{array}$ \\
\hline
\end{tabular}

Keywords: mathematical problem-solving, primary teachers, teaching practices

\section{INTRODUCTION}

Problem-solving is important in today's increasingly interconnected world (OECD, 2017). Competence in solving mathematical problems is recognized in both international educational measurements and many national curricula. Also, the Finnish national core curriculum for basic education (2014) emphasizes pupils' creative and critical thinking and problem-solving skills, as well as their ability to understand different perspectives and phenomena. Pupils are encouraged to solve problems, argue, reason, and make conclusions and new inventions (FNBE, 2014).

In-service teacher training is one way in which to help teachers meet the challenges in teaching problem-solving set by the new curriculum and develop their personal model of teacher competence. One of the key aspects for succeeding in in-service teacher training is the physical presence of pupils (Margolis, Durbin \& Doring, 2017; Sarama, Clements, Wolfe, \& Spitler, 2016). This study is part of the three-year Finland-Chile in-service teacher training research project, financed by the Academy of Finland (project\#1135556, see more in Pehkonen, Näveri, \& Laine, 2013). The project aimed to clarify the development of grade 3-5 pupils' mathematical understanding and problem-solving skills using open problem-solving tasks at least once a month (altogether 20 problems, 20 times 45 minutes lessons). In addition, the project examined how the participating teachers implemented problemsolving lessons, and how these activities affected pupils' solutions (Laine, Näveri, Ahtee, Pehkonen, \& Hannula, 2018). The aim of this paper is to examine the different ways in which the two Finnish primary teachers' beliefs, knowledge and practices interacted when learning to teach mathematical problem-solving. The importance and novelty value of this paper is that we took the opportunity to examine these aspects within this longitudinal, open problem-solving project.

From the teacher's professional perspective, it is essential to consider their beliefs, knowledge and practices (cf. Shulman, 1986, 1987). In the following two chapters we will first discuss the interaction between teachers' mathematical beliefs, knowledge and practices. Then we take a closer look at teachers' problem-solving beliefs and knowledge, open problem-solving tasks, and teaching problem-solving.

\section{TEACHERS' MATHEMATICAL BELIEFS, KNOWLEDGE AND PRACTICES}

Change in teachers' beliefs, knowledge and practices is slow and difficult to grasp, which is why it have been studied extensively (c.f. Stahnke, Schueler \& Roesken-Winter, 2016). It is known that teachers' beliefs about the nature of mathematics, mathematics teaching and pupil learning are strongly reflected in their instructional practices (Kagan, 1992; Thompson, 1984; 
Wilkins, 2008). These beliefs are intertwined and can be extremely resistant to change (Pajares, 1992) or they can change rapidly and profoundly (Liljedahl, 2010). Moreover, teachers often revert to their original beliefs once they transition from theory to practice (Lui \& Bonner, 2016.)

Beliefs constitute a belief system, which means that some of them can be defined as core beliefs and others as peripheral beliefs, and individuals can hold two incompatible, inconsistent beliefs without internal conflict (Cross, 2009). For example, in their study, Lui and Bonner (2016) observed that although teachers held constructivist orientations for mathematics teaching and learning, they could still hold traditional beliefs about what mathematics is (see also Viholainen, Asikainen, \& Hirvonen, 2014). In Cross's study (2009), the data revealed that beliefs about the nature of mathematics can serve as a primary source of teachers' beliefs about pedagogy and pupil learning, and that these three beliefs are rather reliable predictors of the type of instruction that will take place in the classroom (see also Stipek, Givvin, Salmon, \& MacGyvers, 2001). Conversely, Polly, McGee, Wang, Lambert, Pugalee, and Johnson (2013) found no statistical link between teachers' orientation towards mathematics as a subject and their instructional practices. Instead, whether teachers' practices were teacher-centred or student-centred appeared to depend on the teachers' beliefs about mathematics teaching.

Another perspective into teachers' professional perspectives is that of the teacher's knowledge base, which can be seen as a combination of content knowledge, pedagogical knowledge and pedagogical content knowledge - which is a combination of the previously mentioned (see Shulman, 1987). Ball, Thames, and Phelps (2008) suggest that the knowledge of mathematics' pedagogical content can be divided into two sub categories: knowledge of content and pupils, and knowledge of content and teaching. The former combines an understanding of pupils and knowledge in mathematics and includes aspects such as the way in which pupils think, know and learn a specific mathematical content; common pupil errors; and developmental sequences (Hill, Ball, \& Schilling, 2008). The latter combines the knowledge about teaching with knowledge about mathematics and focuses on which examples are appropriate as a starting point, the diverse representations of the concept (Ball \& al., 2008; Blömeke, Busse, Kaiser, König, \& Suhl, 2016), and how to unpack mathematical ideas (Hodgen, 2011).

Knowledge of mathematics content also includes an understanding of mathematical structures which enable the handling of tasks, for example, how to use pictures or diagrams, to represent mathematics concepts and procedures, and to provide pupils with explanations for common rules and mathematical procedures. Moreover, knowledge of mathematics content allows teachers to follow pupils' mathematical thinking, and to evaluate the validity of their solution strategies, their explanations, and solution paths (Ball et al., 2008; Blömeke et al., 2016; Hill et al., 2008) It has been recognized that teachers' knowledge of mathematics content is significantly related to pupil achievement gains. (Hill, Rowan \& Ball, 2005; Oppermann, Anders, \& Hachfeld, 2016).

The third aspect of teachers' professional perspectives, teacher's classroom practices, depends not only on teachers' beliefs but also on their knowledge base and teacher affect. As a rule, we can expect that a teachers' good mathematical content knowledge influences their classroom practices in positive ways. However, teachers' beliefs about the nature of mathematics and the teaching and learning of mathematics have an impact on how they teach mathematics and promote students' mathematical learning; in other words, how they translate their subject knowledge into instruction. (Kutaka, Ren, Smith, Beattie, Edwards, Green, Chernyavskiy, Stroup, \& Lewis, 2018; Hughes, Swars Auslander, Stinson, \& Fortner, 2019). As Swars, Smith, Smith, Carothers, and Myers (2018) formulate it: beliefs influence teachers' thinking and behaviour, and consequently affect their instructional decision-making and their use of curriculum materials.

Teachers' professional knowledge can also be viewed from a situated perspective. (Stahnke et al., 2016.) Santagata and Yeh (2016) link these two perspectives and combine knowledge, beliefs, pupils and practices with the help of competences in their model of teacher competence. They emphasize the situationality of instruction, and that teachers engage in the process of attending to pupils, their abilities, tools, classroom experiences and the teaching community before they make any interpretations or decisions in their class. Therefore, some teachers' beliefs, knowledge and practices may remain unactivated during their teaching (Santagata \& Yeh, 2016, see also Johnson, Severance, Penuel, \& Leary, 2016; Kuntze, 2012). Blömeke and Kaiser (2017) also state that a teacher's classroom practices can be seen as a multi-dimensional, individual match between cognitive and affective-motivational competence and situation-specific skills in particular. By situation-specific skills they mean skills such as perception, interpretation and decision-making. Experienced teachers are competent in observing; their mathematical knowledge helps them perceive and interpret pupils' work, and their knowledge, beliefs and goals influence their in-the-moment decision-making (Stahnke et al., 2016).

Together, all these perspectives lead to observable teacher practices. Sometimes one dimension may be weaker than the others, but the dimensions can also compensate for each other. (Blömeke, Gustafsson, \& Shavelson, 2015; Blömeke et al., 2016). Teaching competences and skills evolve throughout the teacher's career. For example, in Shahbari's study (2017) in-service teachers were better than preservice teachers in all domains of mathematical content knowledge and mathematics pedagogical content knowledge. Such style of knowing is 'not a state of being but a process of becoming-the becoming of a mathematics educational mindset' (Scheiner, Montes, Godino, Carrillo, \& Pino-Fan, 2017, p. 18.) Reflection is assumed to play a key role in changing a teacher's practices. Due to this, many researchers see a cyclical relationship between changing beliefs and changing practices (Lerman, 2002; Wilson \& Cooney, 2002).

\section{TEACHERS' PROBLEM-SOLVING BELIEFS, OPEN PROBLEM-SOLVING TASKS AND TEACHING PROBLEM-SOLVING}

Problem-solving is nowadays seen as an essential part of teaching and learning mathematics in school. By problem-solving beliefs, we mean teacher's beliefs about problem-solving learning, problem-solving teaching, and the relation between building 
pupils' mathematical knowledge and enhancing pupils' mathematical problem-solving abilities (Harisman, Kusumah, \& Kusnandi, 2019).

Chapman (2015) calls mathematics problem-solving knowledge for teaching 'a complex network of interdependent knowledge'. A mathematics teacher should possess problem-solving content knowledge about mathematical problems and problem posing. Furthermore, the teacher should have problem-solving pedagogical content knowledge about pupils as problemsolvers, instructional practices for problem-solving such as heuristics, and the use of technology. In addition to these, the teacher should have knowledge of affective factors and beliefs in mathematical problem-solving and knowledge of mathematical problem-solving proficiency, i.e. understand what is needed for successful mathematical problem-solving (Chapman, 2015).

When teachers are expected to guide problem-solving, it may challenge teachers to move away from their comfort zones and activate their beliefs like self-efficacy beliefs and beliefs about the value of problem solving (Saadati, Cerda, Giaconi, Reyes, \& Felmer, 2019; Schiefele \& Schaffner, 2015). Siswono, Kohar, Rosyidi, and Hartono (2017) found in their study that teachers had sufficient understanding of problem-solving as instruction, problem-posing and problem-solving steps, and of how to implement these in their teaching. However, they had less knowledge of problem-solving content knowledge such as problem-solving strategies and open problems. They did not understand the meaning of the problems or what it meant that the problem had more than one answer (see also Chapman, 2013).

In order to understand what problem-solving is, we have to identify what kind of problems we can use in our teaching. Closed mathematical tasks, which can be found in textbooks, have a determinate answer, a specific goal, and only one possible method or known procedure can solve them (Yeo, 2017). A closed task can be said to be a problem if the solving necessitates the solver to connect his earlier knowledge in a new way (Nohda, 2000). In contrast, an open problem-solving task is considered to require many skills, not only calculating skills, and the openness of the task can appear in different ways. For example, open problemsolving tasks can have an open beginning or an open end, or the solving method can be open (Pehkonen, 1997). Yeo (2017) identified five task variables: goal, method, complexity, answer and extension, and these tasks differ from each other depending on which variables are closed and which are open. He also talks about other aspects such as well-defined, ill-defined, task-inherent and subject-dependent openness. In Yeo's (2017) framework, an open problem-solving task suggests a well-defined goal such as 'find the pattern', or an ill-defined general goal such as 'investigate'. An example of a well-defined, determined goal is 'draw'. A task-inherent method means that the goal does not depend on the teacher or the pupils and is open, for example, 'design a house'. In this task, all the solutions may differ from each other.

Teaching problem-solving and open problem-solving tasks require the teacher to have readiness for pupils' unexpected solutions, as well as teaching flexibility, to initiate the work without revealing the solution, to guide the solution process, as well as to sum up the findings and solutions (e.g. Nohda, 2000). Teachers must also have knowledge of how pupils cope with challenging mathematics, as well as knowledge of appropriate learning settings (Applebaum \& Leikin, 2007). Aintley and Luntley (2007, p. 4) talk about attention-dependent knowledge, which means 'a repertoire of attentional skills for attending to cognitive and affective aspects of pupil activity'.

When we view problem-solving activities more closely in a problem-solving lesson, we can identify three phases (Stein, Engle, Smith \& Hughes, 2008): the launch phase, exploration phase, and the discussion and summarizing phase. To this we can also add a preparatory phase because the teacher makes many of the decisions and does much of the organization before the lesson begins see Figure 1.

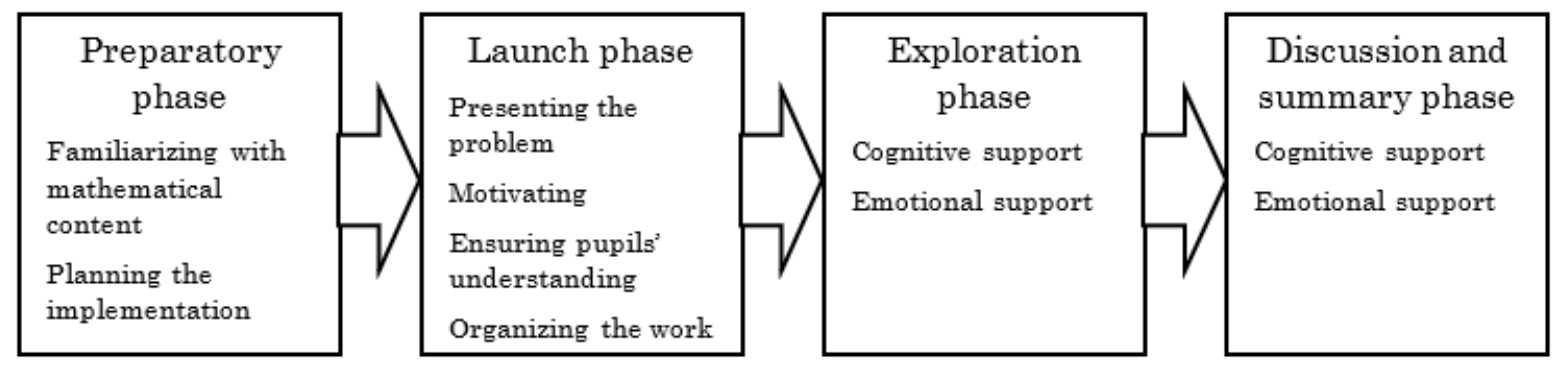

Figure 1. Problem-solving lesson phases adapted from Stein et al. (2008)

During the preparatory phase, teachers familiarizes themselves with the mathematical content of the task, i.e., the phrases, concepts and rules. They plan the implementation of the task and prepare and collect the necessary materials. In the preparatory phase the teacher may adjust the openness of the problem, as they might think that it does not correspond to their teaching objectives or they may not understand the meaning of the problem (Siswono et al., 2017). Sometimes the teacher is unsure about the cognitive demand of the task. Chapman (2013, p. 1) suggests that teachers need mathematical-task knowledge for teaching in order to be able to select tasks which develop students' mathematical thinking and capture with interest.

Despite knowing the benefits of problem-solving tasks, the teacher might also feel uncertain about using them, because they may be too difficult (also for the teacher), and the pupils may lack the necessary background information (Applebaum \& Leikin, 2007). Andersson, White, and Sullivan (2005) concluded in their research that teachers are constantly changing their plans and reacting to their pupils' individual needs and affective states. A teacher may prefer routine mathematical tasks to problem-solving tasks. Hence, teachers often postpone problem-solving tasks until the stage at which they begin to take the shape of more routine tasks (cf. Tzur, 2008; Swan, 2007).

If the teacher decides to use an open problem-solving task, she presents the task to the class during the launch phase. During this phase, the teacher ensures that the pupils understand what they are required to do and motivates them to become as fully 
engaged in the task as possible. The teacher also organizes the work, sets up the materials and informs the pupils of how long the activity will last (Stein et al., 2008; Sawada, 1997). During the launch phase open problem-solving tasks eventually change shape and lead to a different kind of learning to that for which they were originally planned. The task perhaps becomes less open, because the procedures and formulas have already been taught in previous lessons, and the teacher may try to get the pupils to actively recall these before turning to the problem-solving task at hand (cf. Tzur, 2008; Swan, 2007).

During the exploration phase, pupils work on the problem, often discussing it in pairs or small groups. As the pupils work, the teacher is able to hear the thoughts of individual pupils, guide discussions, offer support, and encourage them to go on with solving the problem. Here it is important to provide positive yet realistic feedback to support the pupils' self-confidence and engagement in the task (Linnenbrink \& Pintrich, 2003). Optimally, the teacher will be able to listen to their pupils, to take flexibly into account their needs, and share responsibility while working with them. Pehkonen and Ahtee (2006) have suggested that the most advanced level of listening is empathic listening, when the teacher strives to understand pupils' thoughts and hear, follow and understand their ideas from their viewpoint. The primary intention of empathic listening is to help pupils verbalize their own ideas rather than merely take those of the teacher.

Problem-solving tasks may sometimes change during the exploration phase if the teacher sees that the pupils are not progressing as desired. Sometimes the teacher discovers that pupils are struggling to solve the problem and decides to teach something to help them proceed. At times, the teacher may notice some extra noise in the class or a pupil's poor motivation, and stops the work in order to give more instructions and guide the pupils' mathematical thinking by giving tips or hints. This might change the complexity of the task (see Yeo, 2017). The complexity of the task depends on the pupils and sometimes on the teacher. Too much scaffolding can close the task. Occasionally, the task might also change shape if the teacher decides to shorten the working time (Swan, 2007; Tzur, 2008).

In the discussion and summary phase, the lesson concludes with a class discussion of the pupils' solutions to the problem (Stein et al., 2008). During this phase the whole class views and discusses a variety of approaches to the problem (Sawada, 1997). The teacher must orchestrate this - not merely manage the pupils' interventions and interactions, but also promote the mathematical quality of the pupils' explanations and discussion. The teacher also needs to create and maintain a positive climate of genuine interest in the discussion and try to ensure the participation of all the pupils.

\section{AIM OF THE STUDY AND RESEARCH QUESTIONS}

The aim of this study was to describe how two primary teachers increased their understanding of mathematical problemsolving in a three-year in-service teacher training project. We tried to grasp the interaction between these teachers' beliefs, knowledge and practices within a problem-solving context. In the project all participating teachers were able to try out several open-ended problems with their pupils and thereby learn how to teach problem-solving. The teachers were nevertheless allowed to pose the problems and design the instructional practices in their own ways, and in the process they also learned about their pupils as problem-solvers (c.f. Chapman, 2015). In this three-year longitudinal project, we surveyed these two primary teachers, observing their practices and their ways of guiding open problem-solving tasks in their classes.

Our research question is as follows:

In what different ways can the interplay between two primary teachers' beliefs, knowledge and practices be seen during the three-year project when they are learning to teach open mathematical problems?

In this study, we collected the beliefs from the teachers' interviews. We analysed the knowledge of teaching problem-solving by gathering the teachers' reasoning from their interviews and examining video recordings. We observed the teachers' practices and guidance from the videos, and gathered the teachers' reasoning regarding the practices from their interviews. We also paid attention to the openness of the problem-solving tasks and how the teachers succeeded in keeping the tasks open (see Table 1).

Table 1. Types of Data and How They Were Used in the Study

\begin{tabular}{cc}
\hline Type of data & Purpose \\
\hline Interviews & Beliefs \\
\hline & Reasoning about knowledge of teaching problem-solving \\
\hline Video-recordings & Reasoning about practices \\
\hline & Knowledge of teaching problem-solving \\
\hline
\end{tabular}

\section{Background of the Study}

In the following section we will first say something about the status of problem-solving in teaching mathematics in Finland and then deal more about the Finland-Chile research project. After that we will introduce the two participating teachers who volunteered for this study, and the three open problem-solving tasks we used in the analysis.

The Finnish national curriculum (FNBE, 2014) emphasizes the use of problem-solving, but according to Krzywacki, Pehkonen, and Laine (2016) teachers report not having enough time for this. This is due to the fact that teachers are very loyal to textbooks and even though textbooks also contain problem-solving tasks, it is the teachers who choose whether they want to use these problems in their teaching or not. Most of the tasks in textbooks and teacher guidebooks are not open problems. These closed tasks often suggest some heuristics on how to solve the task, one solution method, and one result. Teachers do not discuss these 
tasks in the classroom, and they seldom ask for different solutions (Krzywacki et al., 2016). The material used in this article was collected during the now completed Finland-Chile research and in-service project. The project was a follow-up study in which the same ten teachers and their teaching groups in the surroundings of Helsinki were monitored from the 3rd grade (age 9) to the 5th grade (age 11). These teachers thus taught the same class for the whole study period of three years. At the beginning of the project, the focus was more on the pupils and their learning about problem-solving, thus the participating teachers were not tested or interviewed at the start.

Once a month, the participating teachers conducted a mathematics lesson in which they used an open problem-solving task. These tasks were selected from a large number of tasks suggested by the project organizers both from Chile and Finland. They had reviewed domestic and international teaching materials and looked for suitable tasks. Altogether, 20 problems dealt with arithmetic (3), geometry (8), combinatorics (6), and real-life situations (3) were selected and then modified to meet the grade levels and curricula in both countries.

In addition, once a month the teachers had a meeting with the researchers. In these meetings, the researchers gave lectures on items related to teaching problem-solving, discussed the implementation and experiences of the previous problem with the teachers, and watched some video extracts of the lessons and of the different phases of the solution process. During the meeting, teachers could also familiarize themselves with the new problem, which had been selected by the research group. They were not given the solution to the task or any normative practices. The teachers were supposed to plan the classroom implementation of the problem by themselves or in co-operation with each other. The researchers did not interfere with this, but provided some information about problem-solving in general, about how to pose questions to the pupils and about heuristics. The teachers developed different practices with their classes and learned from each other. All the meetings with the teachers and the problemsolving lessons were video-recorded.

\section{Participating teachers}

The study that this paper reports focused on two experienced primary teachers, Ann and Beate (pseudonyms), who volunteered to be interviewed.

Ann had been a teacher for about 20 years. She worked in a school with more than 600 pupils and 60 staff members and was involved in a Finland-Chile research project following her school principal's proposal, which she enjoyed. She mentioned that one of her objectives was to develop her skills. She wanted to learn different ways to teach mathematics and gain different perspectives of her pupils' daily work.

Beate had been a teacher for about 10 years. Beate's school had about 400 pupils and 40 staff members. She was immediately enthusiastic about the project, which offered an opportunity to learn to teach problem-solving, which she was not so familiar with at the time. She also wanted to improve her knowledge of mathematical content. Moreover, Beate stressed how important was that participation in the project would be a unique experience for her pupils.

\section{Three open problem-solving tasks}

The open problem-solving tasks used in the Finland-Chile project were tasks in which either the start or the end situation or solution method could all be open (e.g. Pehkonen, 2004). Moreover, these tasks were independent, and their order was irrelevant as they did not require skills which were yet unfamiliar to the pupils (like calculating area) and were in line with the curriculum. To answer the research question, we selected the following three tasks (the implementation time is given in brackets). These problems were selected because they covered the whole project period, and it was possible to follow teachers' development of teaching problem-solving. Moreover, the selected tasks were geometric problems and contained hands-on activities like drawing with crayons and rulers or constructing with peas and toothpicks.

Task 1: Flag with stripes ( $3^{\text {rd }}$ grade, 2011): Design flags with three stripes and three colours. Design as many flags as possible. Draw your solutions.

The 'Flag with stripes' task was the third problem used in the project. It was a drawing problem with an open ending (see Pehkonen, 1997). It had a well-defined goal ('Design as many as possible'), but no clear strategy how to do it. And it had an illdefined subjective answer (the pupils' decided themselves when they had completed the task). The teacher was able to close the task and reduce its complexity by telling the pupils how to start, what method to use or by showing examples. The task could be extended by using curves instead of lines. (see Yeo, 2017). Mathematically, the task developed combinatorial thinking, because the order of the stripes, the width, the direction, and the shape of the stripes could vary. The task also introduced the concept of infinity.

Task 2: Peas and toothpicks (4 ${ }^{\text {th }}$ grade, 2012): Construct three-dimensional objects using toothpicks as edges and peas as vertices. For example, to the construct a cube, you need 12 toothpicks and 8 peas (cf. Figure 2). Build three-dimensional objects that require less than 12 toothpicks. Use only one toothpick per edge. Investigate the objects you have built and write down your observations. Can you justify that you have built all possible objects with 12 toothpicks?

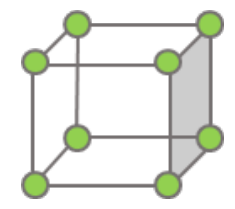

Figure 2. Cube construction built with peas and toothpicks 
The 'Peas and toothpicks' task was the tenth experimental problem in the project. This task was open from the beginning (Pehkonen, 1997). According to Yeo (2017), this task can have a well-defined objective answer ('possible to find all the possibilities') if only convex polyhedra are accepted as correct solutions. The goal was ill-defined ('construct'), and no clear strategy was introduced. The complexity of the task was subject dependent (the pupils decided themselves when they had completed the task). The teacher was able to close the task by telling them the systematics, but in this task, extension was not possible. In this task pupils were able to use their creativity and let go off familiar shapes. The Peas and toothpicks task developed spatial perception skills, and some pupils could also learn how to proceed systematically. By systematics here, we mean first level simple systematics, filling a table: how many vertices, how many edges. Furthermore, the task familiarized pupils with the concepts of plane figures and solids.

Task 3: Largest rectangle ( $5^{\text {th }}$ grade, 2013): Draw various rectangles that have a perimeter of $30 \mathrm{~cm}$. Calculate the areas of these rectangles. Which rectangle has the largest surface area? Can you find any systematics?

The third problem was the 'Largest rectangle' task. In this task the solution method was open (Pehkonen, 1997). According to Yeo's (2017) framework, the answer was well-defined and objective because it was possible to find the solution - a square). The goal was open but well-defined ('draw' and 'calculate'), as was the method (no clear strategy). In this task, as in the previous ones, the complexity was subject dependent (the pupils decided themselves when they had completed the task), and the teacher was able to close the task by suggesting 'think about other numbers, not only natural numbers'. In this task, extension was possible (find a rule). The mathematical purpose of this task was to find the largest rectangle with a perimeter of $30 \mathrm{~cm}$ and to realize that even though the perimeter of each rectangle is the same, the area of the shape can vary. The task required moving from natural numbers to rational numbers and noticing that there is infinite amount of options. However, the largest rectangle is a square. The task developed systematic work and solution strategies. In the Largest rectangle task it was possible for the pupils to learn that a square is also a rectangle.

\section{METHOD}

In the following section we will present the data collection and analytical method.

\section{Data Collection}

The study material consisted of data from two rounds of semi-structured recorded interviews. The interviewer had followed both teachers through their ordinary day and made field notes about her observations. These field notes were used as additional support during the interviews. In addition to these interviews, we used three video-recorded problem-solving lessons given by both teachers as data. When selecting these three problem-solving lessons, we also looked through all the 20 video-recorded problem-solving lessons that had been collected during the academic years 2010-2011, 2011-2012 and 2012-2013 from both teachers and chose one video from each academic year and a task dealing with geometry (8/20 tasks involved geometry).

The first interviews were conducted in April 2012. The main questions in the first interview covered the following areas: teachers' interest in taking part in the project, teacher's career and professional development, mathematics lessons, and pupils' mathematical thinking. Moreover, questions were posed about the teachers' mathematical content knowledge, beliefs concerning mathematics and its teaching, and problem-solving. The teachers were asked whether the problem-solving had made an impact on their teaching and roles, and how they organized the problem-solving lesson.

The second interviews were conducted in May of 2013, when all the problem-solving lessons were over. The themes dealt with mathematical problem-solving and the teachers' professional development. The teachers were able to reflect on how they used problems in their teaching. They were asked about their preparatory phase, the launch phase of the problem-solving activity, the exploration phase and guiding process, and the summary and discussion phase. Furthermore, we asked questions about changes during the project, the challenges they met, and the insights they gained. We also asked about the pupils' learning, as well as the tasks the teachers had employed and the future use of these tasks.

\section{Data Analysis}

The interviews were analysed using directed content analysis by Hsieh and Shannon (2005). The goal of a directed approach to content analysis is to validate or extend an existing theoretical framework or theory (Hsieh \& Shannon, 2005). At the beginning of the analysis we listened to the interviews, transcribed them, read them thoroughly, and watched the lesson videos, in order to form an overall picture of the material (see Schreier, 2012).

To respond to the research question we first began to categorize the content of the interviews and started to construct a large table, in which both teachers had their own column. In separate rows, we recorded the two teachers' beliefs about mathematics, about teaching mathematics and learning mathematics, and beliefs about problem-solving. Then we divided the transcribed lessons into preparatory, launch, exploration, and discussion and summary phases, and selected some extracts from each phase. We placed the interview extracts in which the teachers described the problem-solving phases in the same table as the beliefs (see Table 2). When doing so we could assign successive parts of the material to the categories and reduce the data so to systematically focus on the aspects related to our research question (Schreier, 2012). 
Table 2. An example of our analysis - the case of Ann

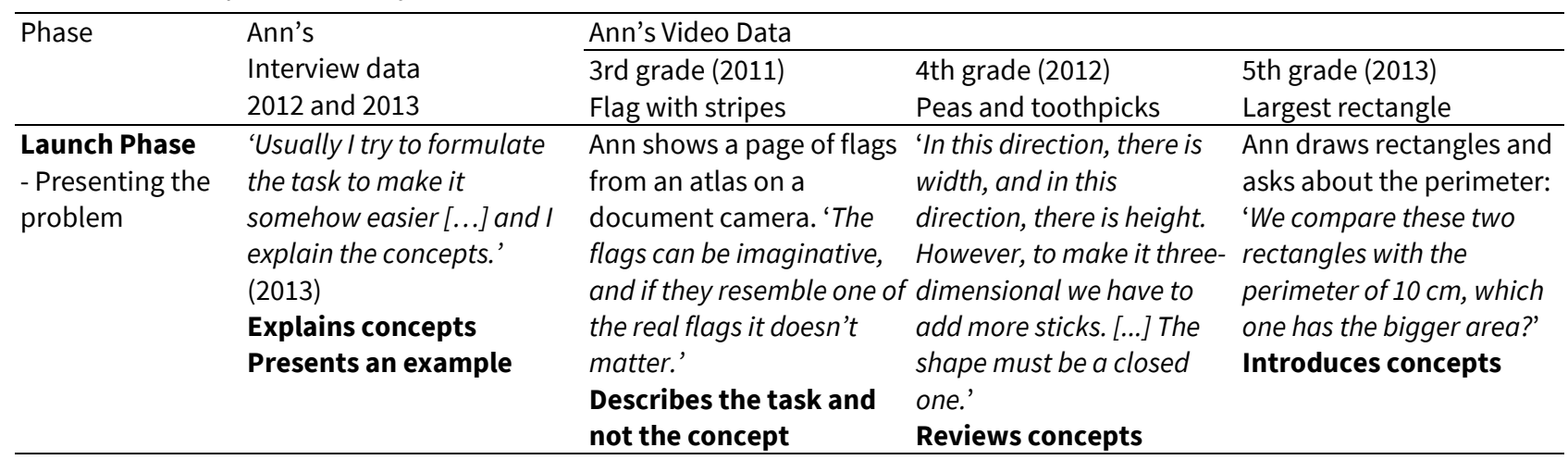

When all the necessary information was either in the table or marked on the videos we began to categorize the material further. The extracts in which the teachers explained how they prepared for the problem-solving lesson (preparations in advance) were divided into two categories: familiarization with the mathematical content, and planning implementation. The extracts in which the teachers explained the way in which they conducted the launch phase (preparations for work) were classified into four categories: motivating the pupils, presenting the problem to the class, ensuring the pupils' understanding of the problem, and organizing the work. As for the exploration phase and the discussion and summary phase, the interview extracts (teacher support) were divided into two categories: the teacher cognitively supporting the pupils' work, and the teacher emotionally supporting the pupils' work.

After this, we looked through the four problem-solving phases in the lesson videos and sought the corresponding categories. Finally, we placed both teachers' video episodes and interview extracts side by side and analysed them. All three authors conducted the analysis, and the process did not progress until consensus was reached.

\section{RESULTS}

Here we give the results from Ann's and Beate's interviews and their practice separately, first Ann's and then Beate's. In both cases we first describe what the teachers communicated about their mathematical beliefs, i.e. their beliefs about mathematics, beliefs about teaching mathematics and beliefs about problem-solving in their interviews. Then we present an analysis of how they guided problem-solving in their classes in the four phases (preparatory, launch, exploration, and discussion and summary phase). Here we have included the relevant extracts from the interviews and from the lessons in the corresponding places to avoid excessive repetition. We also summarize how their practices corresponded with their interview data and encapsulate the findings in the form of tables.

\section{Ann's Mathematical Beliefs}

Ann questions the rigorous essence of mathematics. In the first interview she states: 'I question whether some mathematical rules are bound to be maintained or whether we can think about them some other way' (2012). 'Mathematics is associated with a certain type of structure and systematics, and accuracy. [At the project meetings] people always have to explain it to me in simple words, even the basics' (2012). In the second interview she describes the same thing by saying, 'Systemic thinking ... what's the point... mathematics is NOT how I comprehend this world' (2013).

For Ann, teaching mathematics is to connect it with concreteness. 'I've always liked math, and teaching math, and as I have worked mainly in early primary education we have always used concrete materials' (2012). She also relies on her pupils' ideas. 'I often ask the children for help, how they would explain it to their friends' (2013).

To Ann, mathematical problem-solving is like a challenge that she literally 'throws herself into... Let us tackle the problem not knowing what will come up. And the result may be something completely different from what you have ever thought of (2012). Ann associates learning problem-solving with freedom. 'Pupils are free to choose if they want to work alone, in pairs or in small groups, and all options are possible. I don't want to determine the groups. I think problem-solving is associated with a certain kind of freedom to choose one's way of working' (2012). As she remarks after the project, '[Problem-solving tasks] open up the kind of thinking that there is not always only one right answer. I also think [problem-solving] increases the positive atmosphere in class along with collaborative work' (2013).

\section{Ann's Practice}

\section{Preparatory phase}

Ann prepares the two first problem-solving lessons lightly but for the third lesson she has carefully prepared the structure and the concepts. In the second interview she says that she does not plan the lessons beforehand very well.

'My teaching style is that I do not plan everything beforehand awfully well. I consider the main things in the lesson we should accomplish; what should be at least the minimum outcome' (2013). 
In the 'Flag with stripes' task she has drawn several rectangles on a paper and made copies of these, and she has placed the boxes of the multicolour crayons on the teacher's table. In the 'Peas and toothpicks' task she has soaked the peas overnight and taken these and the given toothpicks with her. In the 'Largest rectangle' task she has placed grid papers with $\mathrm{small} 0.7 \mathrm{~cm} \times 0.7$ $\mathrm{cm}$ squares available in the class on the teacher's table. From the exploration phase it is clear that she has planned the structure and the teaching of the concepts carefully beforehand.

\section{Launch phase}

In the two first problem-solving lessons Ann jumps right into action. She does not take up the necessary concepts - stripe in the 'Flag with stripes' task and solid shape in the 'Peas and toothpicks' task. The pupils are motivated and start immediately to work eagerly. The pupils are allowed to walk around in the classroom and look how the other pupils are working. She does not pay attention to the pupils' understanding of the task. In the third problem-solving lesson Ann spends more time on launch phase. She motivates the pupils referring to familiar objects in the classroom. She goes thoroughly through the necessary concepts. She carefully sets up the idea of the task. In all these lessons Ann deals positively with the pupils and let them work freely without organizing their working.

In the first interview, she says that the pupils start immediately to work with the task.

'In our class the problem-solving tasks start immediately, starting up has never been a problem. The pupils have got into it right away' (2012).

In the second interview she says that she tries to make the task more easily understandable to the pupils.

'Usually I try to formulate the task to make it somehow easier or more easily understandable or more accessible to grasp, and I explain the concepts. It's only then that we start the actual task' (2013).

In the 'Flag with stripes' task Ann motivates the pupils by showing a page of flags from an atlas on a document camera. A discussion follows about the different colours, shapes and figures in the flags, and this seems to have remained in some of the pupils' mind. The assignment of the task is shown the whole lesson in the document camera. Ann does not take up the concept of stripe.

Ann: Today's topic is flags. Let's see what kind of flags there are.

Ann: What do you notice about these flags, how do they differ from one another, are there some similarities?

Pupil 1: Some are more colourful, some less colourful.

Ann: If you think about their shapes, what shapes are there? What shapes have often been used?

Pupil 2: Stars.

Ann introduces the task: Your task is to design flags. The task has some preconditions. Use only three colours, and the flag must have stripes. Choose the three colours you are going to use and remember the flag must have three stripes.

Ann emphasizes: You can draw any kind of stripes, and in any direction. You can decide yourselves. The flags can be imaginative, and if they resemble one of the real flags it doesn't matter.

Ann does not emphasize that the pupils should only use the same three colours. There are lots of colours available, and even though the pupils begin their work with three colours, many of them soon choose other colours. Ann does not check the pupils' understanding of the task. She gives the pupils freedom to organize their work the way they want to. Every pupil gets a paper with rectangles on it, and Ann encourages the pupils to do the planning together with their pairs.

[Ann: You can work in pairs if you want to.]

In the 'Peas and toothpicks' task, Ann introduces first peas and toothpicks. She motivates the pupils by starting to construct a cube. The pupils immediately become excited and want to start making the constructions. The task itself remains unclear, because Ann does not finish the cube.

Ann: Today we have cocktail sticks. Have you seen them, these wooden sticks that have a sharp tip? Then we have peas. Yesterday, I put these here to soak in water so that we will be able to work with them. The idea is that we are going to build solids. I will start by building something, and you can see what it will be. What is this?

Pupil: A square.

Ann: But the square is not three-dimensional, it is two-dimensional. In this direction, there is width, and in this direction, there is height. However, to make it three-dimensional we have to add more sticks. [...] The shape must be a closed one. 


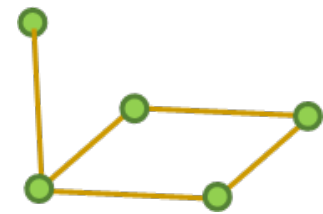

Figure 3. Teacher Ann's unfinished cube

Ann manages to build only a part of a cube (see Figure 3). She introduced the concepts of edges and vertices, but later she calls the vertices incorrectly as 'points'. She asks the pupils to keep record of the number the vertices and edges, and start with 12 toothpicks. Her partly made construction of the cube is shown on the document camera for the rest of the lesson.

In the 'largest rectangle' task Ann had beforehand drawn a rectangle $(2 \mathrm{~cm} \times 3 \mathrm{~cm})$ on the blackboard. She motivates the pupils by asking 'In this classroom, can you find shapes like rectangles?' She goes through the two central concepts rectangle and perimeter in depth. She underlays the idea of the first part of the task. Ann draws two different-sized rectangles ( $3 \times 4$ squares and $2 \times 7$ squares) on the blackboard and asks how the perimeter can be calculated. She measures the height and the width of the first rectangle. The pupils calculate its perimeter.

Ann: Can you draw another rectangle with the same perimeter $10 \mathrm{~cm}$ ?

Pupil: 4 and 1.

The discussion about perimeters and different rectangles continues, Ann notices that she has not explained the third central concept, area.

Ann: How do we calculate the surface area? Can someone tell me how the area could be calculated? Let's figure it out. Oh, but I don't know how to explain it.

One of the pupils explains that the rectangle $(2 \mathrm{~cm} \times 3 \mathrm{~cm})$ can be divided into squares and by counting the squares the area is obtained. Ann shows the task on the document camera, reads it aloud and asks: 'Now that we compare these two rectangles with the perimeter of $10 \mathrm{~cm}$, which one has the bigger area?

She distributes grid papers with $0.7 \mathrm{~cm} \times 0.7 \mathrm{~cm}$ squares. The pupils use rulers to draw the rectangles. Each of them has a paper of their own, but they can work by themselves, in pairs or three pupils together. After the lesson Ann confesses to the researchers that she had forgotten to take up the concept of area beforehand.

\section{Exploration phase}

In the two first problem-solving lessons Ann moves abundantly around the class and deals positively with the pupils. She reminds of the instructions and encourages them to work freely and find more solutions. But she neither tells nor guides them when they are on the wrong track. She appreciates the creativity shown by the pupils, but she does not pay attention to the pupils' understanding of the task. In the 'Largest rectangle' task, Ann emphasizes the key points of the task and steers the process. She encourages the pupils to find a system. She moves less around the class than in the two earlier lessons and then more near the best pupils.

In the first interview Ann says that she moves around the class and discusses with the pupils about their problems to find the solution.

'I move about in the class, and look at the solutions the pupils have come up with. I ask how they figured out the problem and ended up with a particular solution. [...] If a pupil gets stuck, I go to them and together we consider whether something is worth trying. How about this? Or could this be an idea?' (2012).

In the second interview, Ann says that she tries to notice the key point of the task so that she can help the pupils to find the solution.

'I try to notice the key points and see what direction I should point the children in so that they can find the solution. I may have become more aware of the fact that in every task there is something one has to realize first in order to be able to realize something else' (2013).

In the 'Flag with stripes' and 'Peas and toothpicks' task some of the pupils' solutions end up being quite out of the forms (see Figure 4). However, Ann just moves around the class and encourages the pupils. Ann notices that the pupils do not follow the instructions but are drawing other shapes instead of stripes and she accepts the changing of colours. She appreciates the creativity shown of the pupils.

Ann: Your flags are all different. There are different colours and every kind of shape and pattern. There is a variety of forms in what you have used - triangles, stars and circles. But three colours, good. 

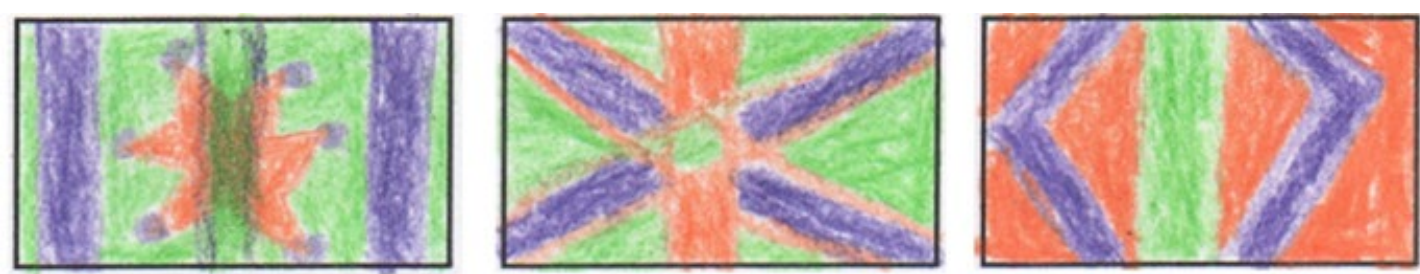

Figure 4. Example of a pupil's 'Flag with stripes' task in Ann's class. These flags reveal that the concept of 'stripe' was unclear

Pupil: Yeah.

Ann: Well, you can choose other colours for the rest of the flags.

However, as the lesson progresses, Ann notices that the task is changing, and no longer allows changing colours.

Ann: You may no longer change colours. Now you have to decide what three colours to use and come up with as many different flags as possible with those colours.

A pupil has taken a smart starting point, the German flag with three horizontal rectangles, black, red and yellow, and then changed the order of the colours.

Pupil: Ann, come and see! Are these correct?

Ann: 'Looks correct, but they do not have to be real. They can be imaginative flags.'

In the 'Peas and toothpicks' task, Ann moves around the class. She always finds something positive to say and encourages the pupils to calculate the amount of peas and the number of toothpicks. Still, in some situations she highlights the task instructions without noticing the problems the pupils are struggling with.

Ann: Calculate how many points and how many edges. These are great!

One pupil has built a cube and discusses it with Ann.

Ann: The cube has eight peas and eight sticks. One, two, three, four, five, six, seven, eight. Wait a minute. There are more than eight sticks. Calculate carefully.

Pupil: Ten.

Even though the answer is wrong, Ann moves on and does not comment on the pupil's construct.

In the 'Largest rectangle' task, Ann emphasizes the key points of the task. She moves around the class very little, but encourages the pupils to find a system.

Ann: What numbers make thirty altogether? For example, 10, 5, 10, 5. I will leave you to think of all the different ways you can get a perimeter of $30 \mathrm{~cm}$. How can you form different combinations? [...] Draw as many rectangles as you can, so that the perimeter is $30 \mathrm{~cm}$ and then calculate which of them has the largest surface area.

Ann has a short conversation with one pupil in the class. They discuss whether the square is a rectangle.

Pupil: Is a square all right, too?

Ann: Yes, a square is also included. After all, it is a rectangle.

\section{Discussion and summary phase}

At the end of the two first lesson described here Ann gathers the pupils' works together and comments them positively even that they are quite out of order as to the task. In the third lesson she tries a small summary in the middle of the lesson. At the end of the lesson she explains the idea of the task very nicely and tell how one pupil had solved the task.

In her first interview, Ann states that in the discussion and summary phase she discusses with the pupils about finding all the possible solutions. It is important to be satisfied with all the pupils' answers.

'In the summary phase we talked through whether these were all the possible options, or whether we could still come up with more. Some children were satisfied with a couple of solutions, and thought that then it was complete, done. Sometimes I asked if there could still be some other solutions and were they sure that it was complete. But if the child was sure that it was ready, okay it was ready, [...] if the child felt it was ready, then it was ready for him at that moment' (2012). 
In the second interview Ann tells that sometimes there can be short discussion and summary sessions earlier in the lesson. She also complains that often the 45-minute lesson is too short for discussion and summary phase.

'I have recently organized a small intermediate summary phase and then we continue the task. In this way you can notice some key elements and still continue with the solutions.' [...] 'The task is often far from being complete and we continue exploring and leave less time for the summary phase. [...] Generally, there is so little time left for the summary, and you could use a lot more time for it' (2013).

In the 'Flag with stripes' task, Ann asks the pupils to present their flags on the document camera (See Figure 4). She comments positively about the pupils' way of changing the colours, about the stripes, the different shapes of the flags, and extra figures in the flags. At the end she asks how the pupils liked the task. And they did like it.

Ann: You first started with these, you got out black and blue and yellow. However, you thought it wasn't nice. Afterwards, you chose orange, green and black and then you coloured that with pink, brown and green. Yeah, at least there are now three colours and three stripes. How about this flag, for example, there are three colours and then there are three stripes. You can think that these are stripes, even if there is indeed a variety of colours used. In your opinion, is this one stripe?

Ann: You have used a variety of shapes. There are triangles and rectangles and then there are stars and circles, but in three colours. Good. There are many different combinations. At this point, I ask you all, how was this task?

Pupils: Fun!

Ann: Was it easy or difficult?

Pupils: Easy! Easy and challenging!

Ann: I noticed that you got quite excited about this.

In the 'Peas and toothpicks' task, Ann collects the pupils' constructions in the same place and photographs them, but there is no discussion. Ann comments positively about the pupils' work.

'These are not closed. They start to have lives of their own. Although, see how cool this is. These are just incredibly cool.'

In the 'Largest rectangle' task, Ann tries to start a small summary about how to produce new rectangles in between the lesson but it fails. Ann notices that one pupil has created a system to produce new rectangles with the same perimeter. Ann asks him to tell the class about it. But he does not want to. The other pupils do not stop working and Ann let them continue.

At the end of the lesson only a short time is left for the summary, but Ann uses it effectively. She explains the system of constructing different rectangles with the same perimeter, and rejoices the fact that the largest rectangle, the square is found. Perhaps the grid papers with small squares is the reason that some pupils discovered that they did not have to use whole centimetres, and it helped them to find the largest rectangle (see Figure 5).

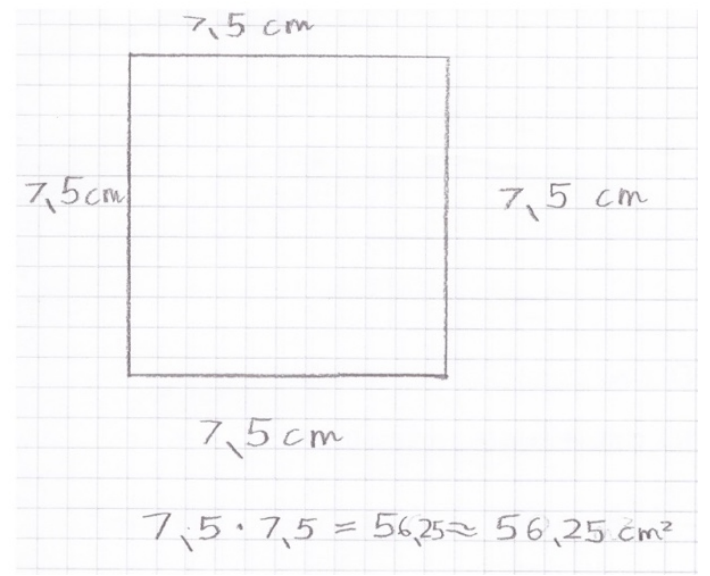

Figure 5. Example of a pupil's Largest rectangle task in Ann's class

Ann: Have you found the largest rectangle?

A group of pupils shout: $7 \times 8=56$.

Ann: It can be modified in such a way that you put one more here and reduce one from here. Then you will get 14 and 1,13 and 2, 12 and 3,11 and 4 .

Ann: You have the largest here, 7.5, 7.5, 7.5, and 7.5. A square is also a rectangle, it covers an area of $56.25 \mathrm{~cm} 2$. We found the largest surface area! 
In Table 3 Ann's views on problem-solving and her actions during the three problem-solving lessons are categorized according to the problem-solving phases preparatory phase, launch phase, exploration phase and discussion and summary phase (c.f. Stein et al., 2008).

Table 3. Ann's views and actions during the problem-solving activities

\begin{tabular}{|c|c|c|c|c|}
\hline \multirow[t]{3}{*}{ Phase } & \multirow{3}{*}{$\begin{array}{l}\text { Interview data } \\
2012 \text { and } 2013\end{array}$} & \multicolumn{3}{|l|}{ Video Data } \\
\hline & & 3rd grade (2011) & 4 th grade (2012) & 5th grade (2013) \\
\hline & & Flag with stripes & Peas and toothpicks & Largest rectangle \\
\hline \multicolumn{5}{|l|}{ Preparatory Phase } \\
\hline $\begin{array}{l}\text { - Familiarizing with } \\
\text { mathematical content }\end{array}$ & No comment & No sign & No sign & Yes \\
\hline $\begin{array}{l}\text { - Planning the } \\
\text { implementation }\end{array}$ & Plans the minimum & $\begin{array}{l}\text { Prepares some } \\
\text { materials }\end{array}$ & $\begin{array}{l}\text { Prepares some } \\
\text { materials }\end{array}$ & Careful plans \\
\hline \multicolumn{5}{|l|}{ Launch Phase } \\
\hline - Presenting the problem & $\begin{array}{l}\text { Explains concepts } \\
\text { Presents an example }\end{array}$ & $\begin{array}{l}\text { Describes the task and } \\
\text { not the concept }\end{array}$ & Reviews concepts & Introduces concepts \\
\hline - Motivating & No comment & Free working & Free working & Free working \\
\hline $\begin{array}{l}\text { - Ensuring pupils' } \\
\text { understanding }\end{array}$ & No comment & No & No & Yes \\
\hline - Organizing the work & No & No & No & No \\
\hline \multicolumn{5}{|l|}{ Exploration Phase } \\
\hline - cognitive support & $\begin{array}{l}\text { Tries to find key points } \\
\text { and direct the pupils' } \\
\text { attention }\end{array}$ & $\begin{array}{l}\text { Reminds of the } \\
\text { instructions } \\
\text { Accepts wrong } \\
\text { solutions }\end{array}$ & $\begin{array}{l}\text { Reminds of the } \\
\text { instructions } \\
\text { Does not revise pupils' } \\
\text { solutions }\end{array}$ & $\begin{array}{l}\text { Focuses on the key } \\
\text { points } \\
\text { Steers the process }\end{array}$ \\
\hline - emotional support & $\begin{array}{l}\text { Encourages pupils } \\
\text { Does not leave the pupils } \\
\text { alone }\end{array}$ & $\begin{array}{l}\text { Moves around and } \\
\text { encourages }\end{array}$ & $\begin{array}{l}\text { Moves around and } \\
\text { encourages }\end{array}$ & Encourages. \\
\hline \multicolumn{5}{|l|}{$\begin{array}{l}\text { Discussion and Summary } \\
\text { Phase }\end{array}$} \\
\hline - cognitive support & $\begin{array}{l}\text { Summarizes } \\
\text { Uses intermediate phase }\end{array}$ & $\begin{array}{l}\text { All pupils present their } \\
\text { solutions }\end{array}$ & No & $\begin{array}{l}\text { Reviews a system Tells } \\
\text { one pupil's solution }\end{array}$ \\
\hline - emotional support & $\begin{array}{l}\text { Appreciates the pupils' } \\
\text { views }\end{array}$ & Praises ideas & $\begin{array}{l}\text { Collects all the } \\
\text { constructions }\end{array}$ & No \\
\hline
\end{tabular}

\section{Beate's Mathematical Beliefs}

In the first interview Beate describes her conception of mathematics in the following way: 'It is logical [...] mathematical thinking, not calculating' (2012). She points out that 'everyday life and mathematical concepts need to be bound together' (2012). In the second interview she describes: 'I think mathematics is both practicing basic calculations and developing thinking skills' (2013).

Teaching mathematics is particularly pleasing to Beate. She emphasizes the structure of a lesson, clear explanation of the concepts and rules, as well as taking all the pupils into consideration. "I really enjoy teaching mathematics. [...] I have a clear vision of what mathematics teaching should be like. I want everyone to learn. [...] Pupils don't learn at the same pace, so I emphasize that they language their thinking' (2012). In the second interview she remarks, 'I have learned to discuss mathematics with the children and I give them more time' (2013).

Beate's thoughts about mathematical problem-solving are practically orientated. She appreciates tasks which work well in the class: 'the tasks should be differentiated for high achievers, and I was surprised during the pair work that the pupils were able to help each other' (2012). In her second interview, she states that 'In fact, what I would stress at the moment is that the pupils should be able to figure things out by themselves, and maybe I could give them some 'rope'. Not everything has to be pre-digested, perhaps smaller and lighter guidelines would allow the pupils to work things out by themselves' (2013).

\section{Beate's Practice}

\section{Preparatory phase}

Beate prepares each task well. She solves the problem beforehand, decides how to present the task, and how to draw conclusions. In the 'Flag with stripes' task she develops a story to motivate the pupils. In the 'Largest rectangle' task she uses this story frame in collecting the pupils' solutions and to connect them to a real-life situation. In the interviews she tells about the importance of solving the task beforehand to see how the task proceeds and in order to understand pupils' ideas.

'I must solve the task first. The teacher's challenge is not to reveal too much too early. So, it's important to understand how the problem-solving task proceeds. When I prepare for the lesson, it sensitizes my ears. If you know what is going to happen, you're able to hear pupils' ideas. [...] You must make mathematics visible and clarify to yourself where you can find mathematics' (2012). 
'Now that my pupils are 5th graders, I always go through the new topic at home. After doing so, I'm able to draw their attention to challenging tasks and explain what makes them difficult' (2013).

In the 'Flag with stripes' task Beate chooses and collects crayons of three colours, copies rectangle papers, and develops a story frame, which she was able to modify in most of the problem-solving lessons. 'Queen Gretel I from Multiplication land was pure coincidence, but the story came alive and it became very special to the children' (2013). In the task 'Peas and toothpicks' she prepares the peas for the lesson and constructs a cube from soft peas and toothpicks. In the 'Largest rectangle' task she prepares a table on which the pupils can list their answers, and takes the copies of it for each pupil. She also prepares a large map about Multiplication land on which the pupils can put their largest rectangle at the end of the lesson.

\section{Launch phase}

In all the three problem-solving lessons Beate first organizes the class, presents a motivation before presenting the task, discusses about the concepts, and ensures that everyone gets started on the task. In the first interview she says that she encourages pupils to think about the task in pairs or in small groups. She also sometimes asks if they need help and teach them strategies. In the second interview, she states that her launch phase has developed during the project. She explains the task in simple words and lets the pupils start with less instructions.

'In the launch phase, I present the task, and encourage pupils to think about it in pairs or in small groups. They seldom work alone. Sometimes I interrupt them and ask if they need help. I teach them strategies and occasionally suggest to them that they should make a drawing, for example' (2012).

'One of my strengths is that I explain it in simple words. Then everyone gets started with the work. Now, I have learned to give more space, and let them start with less and lighter instructions' (2013).

In the 'Flag with stripes' task, Beate starts the lesson with a motivating story by showing an imaginative map of Multiplication land and a drawing of a queen. In the connection of the story she gives the information about the task, organizes the working, and delivers the necessary materials. However, she does not explain the concept of stripe.

'Multiplication land is far away out there somewhere in the Country of Mathematics. [...] Multiplication land is ruled by Queen Gretel I. [...] Well, Gretel is very annoyed about something. Namely, James III from Division land has decided that his country should have a new flag, and Multiplication land doesn't have a flag of its own at all. Now, your goal is to design a flag for Multiplication land. Gretel has one wish, or in fact two. To begin with, the flag must have stripes. And Gretel has decided on the colours. [...]

Design as many flags for Multiplication land as you can. They must all have stripes, and each flag must have three colours: green, yellow and purple. Do you have any questions? You have time to work until Multiplication land's rooster crows three times. Is that OK? Get some crayons for yourself.

Before you start, wait a minute. I've helped you a little bit. I have copied some rectangles so it will be easy to design the flags on them. You can go and work on the floor if you feel that the paper is too big and might not fit on the table.'

In the 'Peas and toothpicks' task Beate first presents the task using the document camera. She draws the pupils' attention to two concepts: edges and vertices. The pupils do not remember them, but she presents her model of a cube, and shows the vertices and the edges. She delivers the answer sheets with the table in which the pupils should fill the number of the vertices and the edges. She divides the task into three phases. In the first phase, the constructions have less than 12 toothpicks.

'In a three-dimensional solid all edges and vertices are connected to each other, otherwise it is open. 'Each of you now work on your own'.

In the 'Largest rectangle' task, Beate begins the lesson by going through the concepts related to rectangle.

Beate: What is a rectangle?

Pupil 1: The opposite sides are of equal length.

Beate: Anything else?

Pupil 2: It is a quadrilateral.

Pupil 3: Four angles.

Beate: What kind of angles?

Pupil 4: The angles are right angles. 
Beate asks the pupils to identify the rectangles from the shown four different rectangles, a parallelogram and a triangle. She then sets the task and asks about the calculation of the perimeter. She delivers $1 \mathrm{~cm} \times 1 \mathrm{~cm}$ squared papers for this task and because the concept of area is new to the pupils, she explains how to calculate the area by counting the squares (see Figure 6).

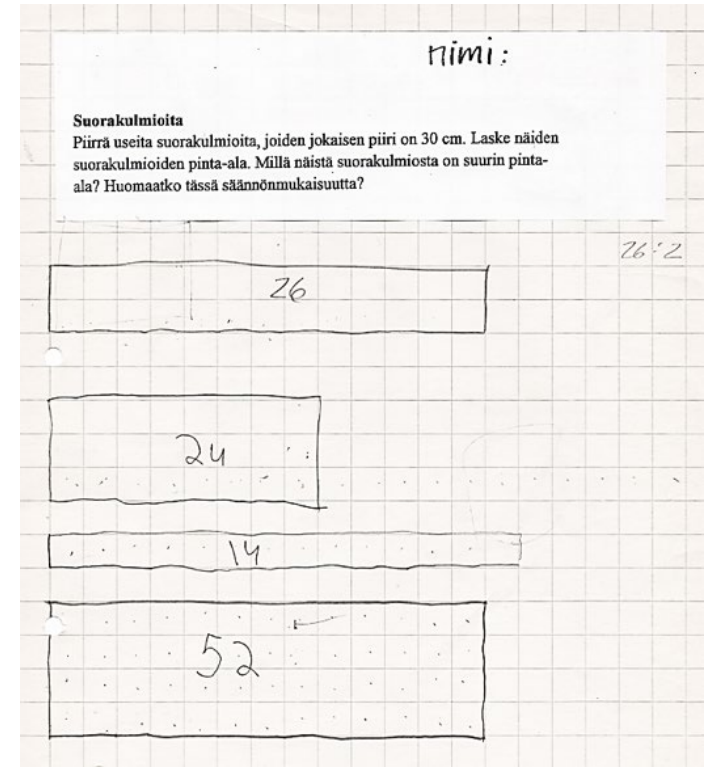

Figure 6. Example of a pupil's Largest rectangle task in Beate's class

\section{Exploration phase}

Beate moves around, encourages and treats all the pupils positively. She helps and guides the pupils in their working toward the right track. She recommends the pupils to look at how others have done. She asks quite a lot of questions. In the first interview Beate emphasizes the importance of appropriate amount of help. In the second interview she points out that she has decreased her guidance.

'In the exploration phase, the challenge is that pupils may not able to start the work, not know what to do, or get stuck. The first is more difficult for the teacher, because if you help too much they solve the task too quickly and without the ' $a$-ha' realization moment. The state of being stuck is easier when you can help them with a small hint. Hey, go and get some ideas from the others!' (2012).

'I definitely verbalize less than I used to. Now and then I have presented a mathematical task without going through the necessary concepts. I just present it, here you are, and ask what shall we do next? Nowadays, I try to just be a bystander. Sure, I walk around and look at what they're doing, and if I notice that they are making a mistake I keep it in mind and correct it later on. I want them to recognize it themselves and think about why they made it. During an ordinary lesson, it's easy to make the mistake of saying there is an error and erase it. I have most certainly developed most in how to discuss mathematics with children, and how to give them time. And I have decided never to present an easier version of a task to someone. If the pupil is facing problems with the task, I organize the work so that they are paired with someone who is able to help' (2013).

In the 'Flags with stripes' task (see Figure 7), Beate moves around and encourages the pupils. She helps the pupils' working quite a lot.
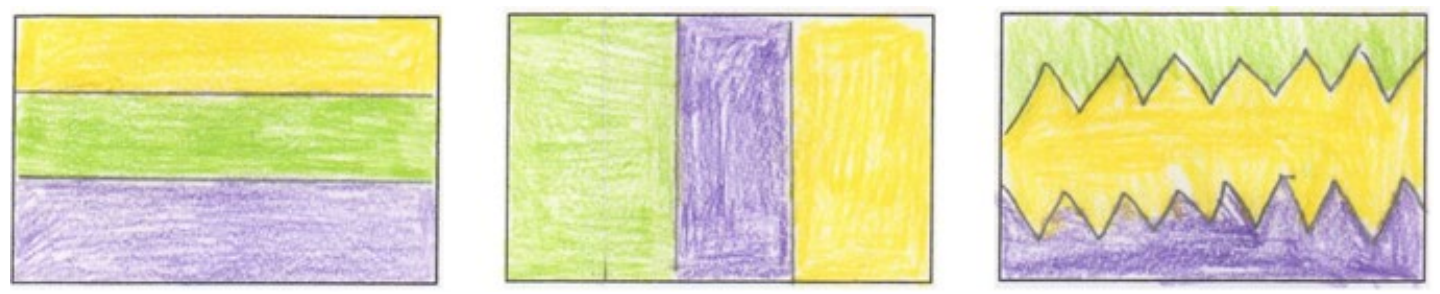

Figure 7. Example of a pupil's Flag with stripes task in Beate's class

'What a fine flag! That's a good idea.

It's a good idea not to use only straight lines.

You can use the same idea again when you change the order of the colours or the directions of the stripes.' 
In the 'Peas and toothpicks' task, Beate circles and urges the pupils to look at what their friends have done, whether they have created something different. She praises the pupils' solutions and asks about the number of vertices and edges, as well as the name of the construction.

'Good, can you find any other solutions?'

When the construction does not comply with the requirements, she points this out. 'All the edges had to be connected.'

In the 'Largest rectangle' task, Beate spends a good deal of time moving about, organizing the work, and ensuring that everyone gets started. She asks questions to strengthen the concepts and helps the pupils to verbalize their thinking. She also guides them to look for systematics.

'Be accurate, the perimeter should be 30 squares.

How about the surface area?

Was this the first rectangle you found? Many of you figured this out first.' [Points to the $5 \mathrm{~cm} \times 10 \mathrm{~cm}$ rectangle]

Two girls are sitting on the floor and ask for help. Beate sits down with them, helps them draw the first rectangle and calculate its sides and area. Two other girls have discovered a rule that could be applied.

Pupil: All the areas are even numbers.

Beate: How did you figure that out? Interesting! Are these all the possibilities you can find? Can you find systematics in these? Now you have so many rectangles that you can make your conclusions.

\section{Discussion and summary phase}

Beate gathers all the pupils' solutions together to be discussed. She also uses a 'half-way summary'. In the first interview Beate emphasizes the importance of the summary phase to highlight mathematical thinking. In the second interview she tells that earlier she thought it important that all the pupils' solutions were shown. Now she thinks that it is important to discuss about an interesting solution so that the pupils will learn. She also says that together the class can reflect on mathematics when they talk how to solve the task in the middle of the lesson.

'The importance of the summary phase is that it highlights mathematical thinking. Pupils have to verbalize their thinking. The more they talk, the clearer things become. Moreover, they may notice that "aha, they were thinking about it that way, we didn't realize that" or "hey, we did that too". Sometimes everyone solves it in the same way, sometimes there are different starting points' (2012).

'In the beginning my aim was to enable as many pupils as possible to show their solutions. Nowadays, I ask for volunteers, or pick some interesting or insightful solutions, and we discuss them all together. The most important thing for me at the moment is to save time for discussion and summing up. It's so very easy for the teacher to read a pupil's face and notice that they are stuck, and then act as a saviour. Instead, we should challenge the children, and in the summary phase at the latest, they realize their mistakes and they learn' (2013).

'I have learned that things can be put together, and that together the class can reflect on mathematics. Nowadays there are more discussions in my class. We might start to talk about how to solve some task right in the middle of the lesson, and whether anybody has figured out how to solve it' (2013).

In the 'Flag with stripes' task, Beate attaches all the pupils' solutions to the blackboard, and together they make some conclusions.

Beate: What does the line not have to be?

Pupil: It does not have to be straight. (see Figure 7)

In the 'Peas and toothpicks' task, Beate makes a short 'half-way summary' in the middle of the lesson, and after that the pupils continue their working. She shows some typical solutions and asks about their names. There are pyramids and tetrahedrons, and 'tents' as she calls the triangular prisms (see Figure 8).

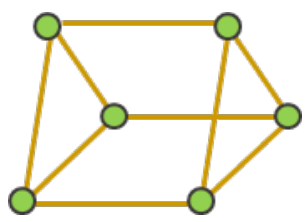

Figure 8. 'Tent' 
The task continues with more than 11 toothpicks but a maximum of 16 , and further with a maximum of 24 or 32 edges. At the end of the lesson, the pupils label and organize the constructions into groups, but there is no time to make any conclusions.

Beate assures: We'll classify them later.

In the 'Largest rectangle' task the pupils have found the systematics, and the largest rectangle in the case of integers.

Beate shows the method how to find the necessary rectangles by picking up a solution of a group of the pupils: 'If you start with a $1 \mathrm{~cm} \times 14 \mathrm{~cm}$ rectangle, and then you lengthen one side by $1 \mathrm{~cm}$, the other side shortens by $1 \mathrm{~cm}$, then you can draw all the possible solutions.'

Beate gathers the pupils to sit around a large paper on which she has drawn the map of the familiar Multiplication land. Each group of the pupils can buy a piece of land by placing on the map the picture of their largest rectangle with a perimeter of $30 \mathrm{~cm}$.

Table 4 depicts Beate's views of problem-solving and her actions during the problem-solving lessons, categorized according to the problem-solving phases preparatory phase, launch phase, exploration phase and discussion and summary phase (c.f. Stein et al., 2008).

Table 4. Beate's views and actions during the problem-solving activities

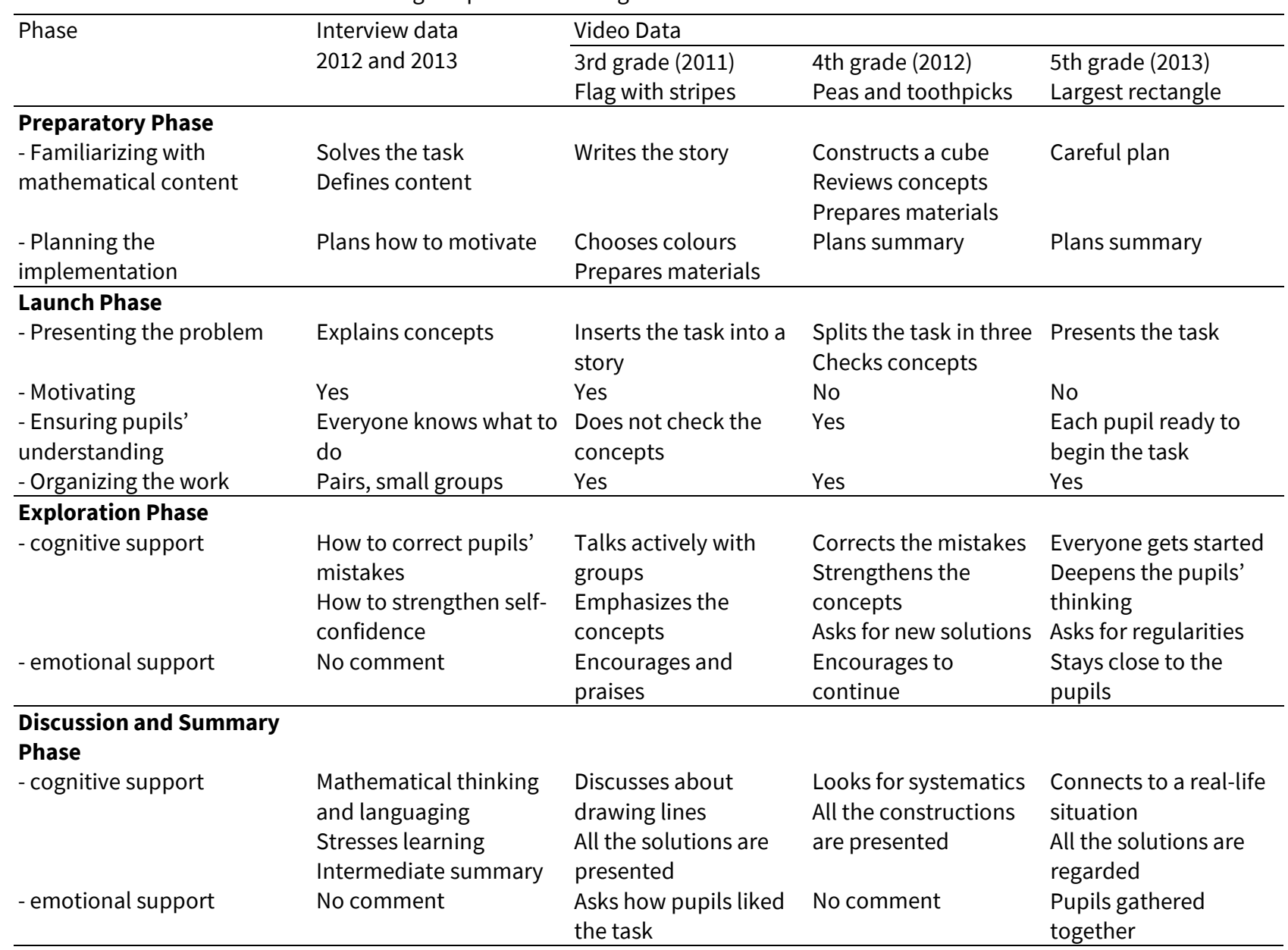

\section{DISCUSSION AND CONCLUSIONS}

In this paper we introduce two primary teachers, Ann and Beate, as examples of the different ways the interplay between teachers' beliefs, knowledge and practices can be seen during the three-year project when they are learning to teach open mathematical problems. The observations were made while watching problem-solving lesson videos and in semi-structured interviews. Ann and Beate had participated in a three-year research project concerning developing pupils' mathematical problemsolving abilities (see Margolis et al., 2017; Sarama et al., 2016). In this project, Ann and Beate had learned about problem-solving strategies and lesson phases and taught mathematical open-ended problems. The focus in the Finland-Chile project was not on the mathematical content of these tasks, and the teachers were free to organize their classroom work in the way they wanted. We want to emphasize that Ann and Beate are both experienced and good teachers, well above average. Here we concentrate more on certain differences in their way to teach mathematics in these three problem-solving lessons. 


\section{Interplay Between Beliefs and Practices}

According to her interviews, Ann saw mathematics as calculations and procedures, and questioned the rigorous demand of these. In teaching mathematics she liked to use concrete materials and relied on her pupils' ideas. To her mathematical problemsolving was like a challenge to throw into. Furthermore, she associated learning problem-solving with freedom. During the first two lessons considered here, she appeared to place little value on mathematical rules and systematic thinking. Instead she always found something positive to say like in the 'Flag with stripes' problem: Your flags are all different. ... But three colours, good. In the two first lessons the tasks contained hands-on materials and the whole class jumped right into action. Ann enjoyed that and let her pupils to work freely. She did not introduce the necessary mathematical concepts. She encouraged the pupils in their working, but she did not pay attention to pupils' understanding of the tasks. In the 'Peas and toothpicks' task, Ann pointed out to a pupil that there were too many sticks in his cube but she did not give any advice or hint how to improve his construct. On the contrary, in the 'Largest rectangle' task in the third lesson containing more ordinary mathematics she had prepared the lesson plan beforehand, motivated the pupils in a mathematical way, revised the necessary concepts, and carefully set up the idea of the task. All the time the structure of the lesson was well in hand. Furthermore, the pupils were free to walk around in the classroom and look what the other pupils were doing like during the earlier lessons. In the two first lessons mathematics in the task was lost but in the third lesson it was well achieved. Altogether, in Ann's class the pupils' freedom to use their own ideas and try out different things was the most visible feature and most of the pupils were actively working with the problem.

For Beate, on the other hand, mathematics was logical thinking and enjoyable; something one can connect to everyday life. In her interviews she emphasized the importance of the role of teaching mathematics. She discussed how she strived to connect the tasks to the curriculum, and how she wanted her pupils to understand what they are doing and thereby succeed in these problemsolving project tasks (c.f. Swars et al., 2018). In her first interview she commented that she was surprised that in pair work the pupils were able to help each other. She prepared thoroughly all the lessons. She organized the class for working, she motivated the pupils before presenting the task, and she introduced the necessary concepts. In the 'Peas and toothpicks' task Beate first presented the task using the document camera. As the pupils did not remember the necessary concepts, she presented her own model of a cube, and showed the vertices and the edges. At the end of the lessons she gathered the pupils' solutions to be discussed. She walked around the class, encouraging and by asking questions she guided the pupils toward the right track. She paid attention to all the pupils and treated them positively. The good organization and systematic working were noteworthy in Beate's class. Even that the pupils were allowed to walk around the class and see what the others were doing the positive activeness to find solutions as found in Ann's class was missing.

We can conclude that in this study, beliefs in mathematics seemed to work together with how the teachers orchestrated their problem-solving lessons, and their dispositions in terms of mathematics teaching and learning and their enacted instructional practices seemed to operate in parallel (see Cross, 2009; Lui \& Bonner, 2016; Polly et al., 2013). Ann experienced mathematics as a rigorous subject and protested against this by giving her pupils much freedom and autonomy. The consequence was that in the two first open-ended problems mathematics was lost, tasks became too open, but the pupils were eager to provide their outputs. Beate believed in mathematical thinking and its importance, but in order to enhance this, she restricted the pupils' freedom and autonomy. Although she recognized this at the end of the project and emphasized it in her interview, she did not really put the realization into practice.

\section{Interplay between Problem-Solving Knowledge and Practices}

The interplay between problem-solving knowledge and practices was observed from the lesson videos and the findings were divided according the problem-solving phases.

Ann did not always prepare her lessons profoundly and pay enough attention to what materials would be the most suitable for each problem-solving task, and how to introduce the task (see Ball et al., 2008; Chapman, 2013). In the launch phase of the 'Flag with stripes' task she motivated the pupils with a familiar topic and they looked at the flags from the atlas, and in 'Peas and toothpicks' task she had prepared the material and she showed how to use it. But in both cases she overlooked the importance of taking up the necessary concepts - stripe and solid shape. In the 'Largest rectangle' task she asked the pupils to tell real examples of rectangles and she introduced the two main concepts, rectangle and perimeter well, and calculated together with the pupils the perimeters of some rectangles. During the exploration phase Ann emphasized the pupils' own activities and freedom and for example in the 'Flag with stripes' task let the pupils change colours all the time and add extra figures. She accepted triangles, stars and circles in the pupils' flags. Thereby the idea of combinatorics disappeared. The same thing happened again in the 'Peas and toothpicks' task when Ann accepted all constructions (see Applebaum \& Leikin, 2007). Ann's guidance based more on encouragement and emotional support than on cognitive support. Pupils' creative ideas were more important to her. Moreover, she was confident of the pupils' abilities to help each other and her pupils also had the courage to do so (see Stahnke et al., 2016). In the discussion and summary phase Ann usually accepted the pupils' solutions even though they might have been wrong or invalid (c.f. (Linnenbrink \& Pintrich, 2003). However, in the 'Largest rectangle' task while circling in the classroom Ann had noticed that a pupil had an idea of how to construct new rectangles, so she took this idea up in the summary phase.

Beate prepared her lessons carefully in advance. She checked the concepts and definitions beforehand and selected highquality material which could best serve the problem-solving task at hand (see Ball et al. 2008; Blömeke et al., 2016; Hodgen, 2011; Kutaka et al., 2018). For example, in the 'Flag with stripes' task she had already chosen the three colours to be used and through this, guided the task into combinatorics. She wanted to know how the problem-solving task would proceed so as to be able to catch the moments when guiding was needed (see Applebaum \& Leikin, 2007). In the launch phase, Beate ensured the pupils' understanding of the key concepts and checked that each pupil knew how to begin the task. Although she had prepared the lesson thoroughly and organized the work so that it would proceed smoothly, she continuously guided her pupils' work during the lesson. 
She tried to deepen their thinking and encourage them to look for regularities. For example, in the 'Peas and toothpicks' task she introduced a table and encouraged her pupils to fill in the vertices and edges to keep track of what they were doing. Beate's actions during the exploration phase were active, she relied on both emotional and cognitive support. She often asked if the pupils could continue from what they had already solved and encouraged them to go around the class fishing for ideas and seeing what others had done. Her emotional support emphasized perseverance. However, in her scaffolding she gave explicit advice and this may have restricted the pupils' ideas and creativeness. In doing so, she left only some free space for her pupils' own thinking and experimenting. Fortunately, in the last interview she seemed to have noticed this herself, even though it was not yet evident in her behaviour in the next last problem-solving lesson with the 'Largest rectangle' task. In the discussion and summary phase, Beate used cognitive support, summarized the key concepts and mathematical ideas, and asked her pupils to language their thinking (see Ball et al., 2008; Blömeke et al., 2016; Hill et al., 2008). She also provided emotional support by asking every group or pair to show their solutions.

We can conclude that teacher's activities during problem-solving lessons reflect how they are able to recognize or interpret mathematical situations in the classroom (Aintley \& Luntley, 2007). When we observe teachers in their classes, we note the way in which they organize their teaching to support the pupils' learning of mathematics. We also determine whether they identify their pupils' mathematical discourse or identify their learning problems (Taylor, Fraser, \& Fisher, 1997). During the three-year project, both Ann and Beate became familiar with the basic elements of problem-solving lessons and how to use open problems in their teaching. In the meetings they began to understand the importance of the final summary, pupils' self-assessment, and the specific role of pupil feedback. While trying out the 20 open-ended problem-solving tasks they gained experience in how to present the problem, how to use ready-made templates, and how to use checkpoints in between (see also Pehkonen \& Portaankorva-Koivisto, 2015; Siswono \& al., 2017). Still, deficiencies in mathematics sometimes seemed to limit their ability to guide problem-solving tasks in a mathematically successful direction and narrowed their opportunities to plan problem-solving lessons coherently. Moreover, when emphasizing concrete materials and creativeness in drawing or building, the focus of the task moved away from mathematical aspects towards concentrating on activities.

\section{Challenges in Teaching Problem-Solving}

During our study we learned that also experienced teachers meet at least two challenges when teaching problem-solving. The first of them is the openness of the task i.e. how not to close the task when preparing the lesson, introducing the problem, and when guiding the problem-solving work. We noticed that the openness of these three problem-solving tasks changed during the lesson activities (see Swan, 2007; Tzur, 2008). The 'Flag with stripes' task changed in Ann's class when she allowed her pupils to change the colours and shapes. The result was that only a couple of her pupils noticed the combinatorial aspect of the task. In Beate's class the combinatorial aspect was achieved, but the various possibilities how to change the stripe remained limited and Beate was not able to extend the problem further (see Yeo, 2017). In the 'Peas and toothpicks' task Ann's version of the task was too open. It resulted in imaginative constructions and the mathematical aspects, such as what is a solid shape, were not debated. In Beate's class finding different constructions was systematic, but this was due to strict task organization and guidance. The pupils filled the edges and vertices in a table. In this task this worked well, because the problem had a closed end. Nevertheless, strict organization can lighten the complexity of the task (see Yeo, 2017). In the 'Largest rectangle' task Ann did not emphasize the systematic search for different rectangles, but she raised one solution method in the discussion. On the contrary, in Beate's class the pupils used a systematic search, but in stressing how to calculate the area of the rectangle by counting the squares, they ended up thinking of integers.

The second challenge is the pupils' autonomy i.e. how to guide both emotionally and cognitively so that the pupils have perseverance, creativeness and joy while solving the problems. In this respect, Ann and Beate were almost opposites. Ann relied on the pupils, asking them to help, strengthened their self-confidence, and in this way also their learning. Beate in turn valued the structure of mathematics and tried on all occasions to help her pupils as much as possible. At the same time, however, she unintentionally restricted her pupils' autonomy to think. Open problem-solving contexts combine two elements: autonomy and mathematical understanding. These aspects are quite clear in Ann's and Beate's behaviour: Ann emphasized autonomy, and Beate mathematical understanding. Moreover, the consequences of these features for the pupils' learning were quite clear. In Ann's class, the pupils could reach their best, whereas in Beate's class, the pupils reached what their teacher could reach.

\section{To Conclude}

As the main conclusion we want to stress that in teaching open problem-solving pupils seem to need autonomy to be creative, as well as mathematical understanding to develop their mathematical thinking. So, the ideal problem-solving instructor is a teacher, who emphasizes autonomy like Ann and takes care of the mathematical contents like Beate. However, there is no one right standard to teach problem-solving. Very different teachers with very different practices can succeed, if they only take into account both mathematical contents and student autonomy.

In this in-service teacher training project, we noted that learning to teach problem-solving is a complex and time-consuming process. Not even a three-year project is long enough for all participants to learn all the aspects concerning teaching problemsolving (see Scheiner et al., 2017). However, we also agree that not many teachers have the possibility and resources to attend a long in-service training. Thereby in the future there is a need for continuity of shorter courses, which are limited to fewer objectives at a time. Moreover, there is also a need to reach a wider range of teachers. On the basis of this project an open problem-solving MOOC (massive open online course) was developed, in which teachers can participate online.

It is not enough that teachers only learn about teaching problem-solving techniques. To be able to influence teachers' practices in teaching problem-solving we must immerse ourselves also in their beliefs. Teachers should learn the features of the 
teacher development process, how these features work together, and how teachers can become aware of their strengths, weaknesses and development targets. This is a long process.

\section{LIMITATIONS}

By critically reviewing our study we saw some limitations. Although the project lasted three years, and ten teachers and their classes participated, only two of the teachers volunteered to be interviewed. Two teachers can only act as examples when studying teachers' beliefs, knowledge and practices in mathematical problem-solving contexts. These teachers' actions and practices also varied greatly depending on the task at hand and how well they knew the mathematics the task required. Another limitation is that we conducted the analysis using videos and interviews and had to rely on the teachers' own descriptions. However, as we had followed the teachers for three years, we had become acquainted with their behaviour from the videos of the 20 problem-solving lessons. In this article we concentrated on teachers' problem-solving knowledge. We understand that when implementing a problem-solving lesson, teachers do not necessarily express all their mathematical beliefs and knowledge that emerge in ordinary mathematics teaching. This is because the objectives of a problem-solving lesson differ from those of an ordinary mathematics lesson (see Chapman, 2015).

\section{ACKNOWLEDGEMENTS}

This study was part of the comparative research project between Finland and Chile 2010-2013, a research project funded by the Academy of Finland (project \#1135556) and CONICYT in Chile (project \#AKA 09).

\section{REFERENCES}

Ainley, J., \& Luntley, M. (2007). The role of attention in expert classroom practice. Journal of Mathematics Teacher Education, 10(1), 3-22. https://doi.org/10.1007/s10857-007-9026-z

Anderson, J., White, P., \& Sullivan, P. (2005). Using a schematic model to represent influences on, and relationships between, teachers' problem-solving beliefs and practices. Mathematics Education Research Journal, 17(2), 9-38. https://doi.org/10.1007/BF03217414

Applebaum, M., \& Leikin, R. (2007). Teachers' conceptions of mathematical challenge in school mathematics. In J. H. Woo, H. C. Lew, K. S. Park, \& D. Y. Seo (Eds.), Proceedings of the 31st Conference of the International Group for the Psychology of Mathematics Education (pp. 9-16). Seoul: PME 2.

Ball, D. L., Thames, M. H., \& Phelps, G. (2008). Content knowledge for teaching what makes it special? Journal of teacher education, 59(5), 389-407. https://doi.org/10.1177/0022487108324554

Blömeke, S., \& Kaiser, G. (2017). Understanding the development of teachers' professional competencies as personally, situationally and socially determined. In D. J. Clandinin \& J. Husu (Eds.), International handbook of research on teacher education (pp. 783-802). London: Sage. https://doi.org/10.4135/9781526402042.n45

Blömeke, S., Busse, A., Kaiser, G., König, J., \& Suhl, U. (2016). The relation between content-specific and general teacher knowledge and skills. Teaching and Teacher Education, 56, 35-46. https://doi.org/10.1016/j.tate.2016.02.003

Blömeke, S., Gustafsson, J.-E., \& Shavelson, R. (2015). Beyond dichotomies: Competence viewed as a continuum. Zeitschrift für Psychologie, 223, 3-13. https://doi.org/10.1027/2151-2604/a000194

Chapman, O. (2013). Mathematical-task knowledge for teaching. Journal of Mathematics Teacher Education, 16(1), 1-6. https://doi.org/10.1007/s10857-013-9234-7

Chapman, O. (2015). Mathematics teachers' knowledge for teaching problem solving. LUMAT, 3(1), $19-36$. https://doi.org/10.31129/lumat.v3i1.1049

Cross, D. I. (2009). Alignment, cohesion, and change: Examining mathematics teachers' belief structures and their influence on instructional practices. Journal of Mathematics Teacher Education, 12(5), 325-346. https://doi.org/10.1007/s10857-009-9120-5

FNBE. (2014). Finnish National Board of Education, National Core Curriculum for Basic Education 2014. Helsinki: Finnish National Board of Education. Retrieved from http://www.oph.fi/english/curricula_and_qualifications/basic_education

Harisman, Y., Kusumah, Y. S., \& Kusnandi, K. (2019). Beliefs of junior high school teachers on learning process on mathematical problem solving. In Journal of Physics: Conference Series (Vol. 1157, No. 3, p. 032112). IOP Publishing. https://doi.org/10.1088/1742-6596/1157/3/032112

Haukoos, G.D., \& Penick, J.E. (1987). Interaction effect of personality characteristics, classroom climate, and science achievement. Science Education, 71(5), 735-743. https://doi.org/10.1002/sce.3730710510

Hill, H. C., Ball, D. L., \& Schilling, S. G. (2008). Unpacking pedagogical content knowledge: Conceptualizing and measuring teachers' topic-specific knowledge of students. Journal for Research in Mathematics Education, 39(4), 372-400.

Hill, H. C., Rowan, B., \& Ball, D. L. (2005). Effects of teachers' mathematical knowledge for teaching on student achievement. American educational research journal, 42(2), 371-406. https://doi.org/10.3102/00028312042002371 
Hodgen, J. (2011). Knowing and identity: A situated theory of mathematics knowledge in teaching. In T. Rowland, \& K. Ruthven (Eds.), Mathematical knowledge in teaching (pp. 27-42). Dordrecht, The Netherlands: Springer. https://doi.org/10.1007/978-90481-9766-8_3

Hsieh, H.-F., \& Shannon, S.E. (2005). Three approaches to qualitative content analysis. Qualitative Health Research, 15(9), 12771288. https://doi.org/10.1177/1049732305276687

Hughes, P., Swars Auslander, S., Stinson, D. W., \& Fortner, C. K. (2019). Elementary teachers' mathematical beliefs and mathematics anxiety: How do they shape instructional practices? School Science and Mathematics, 119(4), $213-222$. https://doi.org/10.1111/ssm.12329

Johnson, R., Severance, S., Penuel, W. R., \& Leary, H. (2016). Teachers, tasks, and tensions: Lessons from a research-practice partnership. Journal of Mathematics Teacher Education, 19(2-3), 169-185. https://doi.org/10.1007/s10857-015-9338-3

Kagan, D. M. (1992). Implications of research on teacher belief. Educational Psychologist, 27(1), 65-90. https://doi.org/10.1207/s15326985ep2701_6

Krzywacki, H., Pehkonen, L., \& Laine, A. (2016). Promoting mathematical thinking in Finnish mathematics education. In H. Niemi, A. Toom, \& A. Kallioniemi (Eds), Miracle of education: The principles and practices of teaching and learning in Finnish schools (Second revised edition, pp. 109-123). Rotterdam: Sense Publishers. https://doi.org/10.1007/978-94-6300-776-4_8

Kuntze, S. (2012). Pedagogical content beliefs: Global, content domain-related and situation-specific components. Educational Studies in Mathematics, 79(2), 273-292. https://doi.org/10.1007/s10649-011-9347-9

Kutaka, T. S., Ren, L., Smith, W. M., Beattie, H. L., Edwards, C. P., Green, J. L., Chernyavskiy, P., Stroup, W., \& Lewis, W. J. (2018). Examining change in K-3 teachers' mathematical knowledge, attitudes, and beliefs: the case of Primarily Math. Journal of Mathematics Teacher Education, 21(2), 147-177. https://doi.org/10.1007/s10857-016-9355-x

Laine, A., Näveri, L., Ahtee, M., Pehkonen, E., \& Hannula, M. S. (2018). Connections of Primary Teachers' Actions and Pupils' Solutions to an Open Problem. International Journal of Science and Mathematics Education, 16(5), 967-983. https://doi.org/10.1007/s10763-017-9809-3

Lerman, S. (2002). Situating research on mathematics teachers' beliefs and on change. In G. C. Leder, E. Pehkonen, \& G. Törner (Eds.), Beliefs: A hidden variable in mathematics education (pp. 233-243). Dordrecht: Kluwer. https://doi.org/10.1007/0-30647958-3_14

Liljedahl, P. (2010). Noticing rapid and profound mathematics teacher change. Journal of Mathematics Teacher Education, 13(5), 411-423. https://doi.org/10.1007/s10857-010-9151-y

Linnenbrink, E. A., \& Pintrich, P. R. (2003). The role of self-efficacy beliefs in student engagement and learning in the classroom. Reading \& Writing Quarterly: Overcoming Learning Difficulties, 19(2), 119-137. https://doi.org/10.1080/10573560308223

Lui, A. M., \& Bonner, S. M. (2016). Preservice and inservice teachers' knowledge, beliefs, and instructional planning in primary school mathematics. Teaching and Teacher Education, 56, 1-13. https://doi.org/10.1016/j.tate.2016.01.015

Margolis, J., Durbin, R., \& Doring, A. (2017). The missing link in teacher professional development: student presence. Professional Development in Education, 43(1), 23-35. https://doi.org/10.1080/19415257.2016.1146995

Nohda, N. (2000). Teaching by open-approach method in Japanese mathematics classroom. In T. Nakahara, \& M. Koyama (Eds.), Proceedings of the $24^{\text {th }}$ conference of the international group for the psychology of mathematics education (pp. 39-53). Hiroshima: PME.

OECD (2017). "How does PISA measure students' ability to collaborate?", PISA in Focus, No. 77, Paris: OECD Publishing. https://doi.org/10.1787/f21387f6-en

Oppermann, E., Anders, Y., \& Hachfeld, A. (2016). The influence of preschool teachers' content knowledge and mathematical ability beliefs on their sensitivity to mathematics in children's play. Teaching and Teacher Education, 58, 174-184. https://doi.org/10.1016/j.tate.2016.05.004

Pajares, F. (1992). Teachers' beliefs and educational research: Cleaning up a messy construct. Review of Educational Research, 62(3), 307-332. https://doi.org/10.3102/00346543062003307

Pehkonen, E. (1997). Use of problem fields as a method for educational change. In E. Pehkonen (Ed.), Use of open-ended problems in mathematics classroom (pp. 73-84). University of Helsinki. Department of Teacher Education. Research Report 176.

Pehkonen, E. (2004). State-of-the-art in problem solving: Focus on open problems. In H. Rehlich, \& B. Zimmermann (Eds.), ProMath Jena 2003, Problem Solving in Mathematics Education (pp. 93-111). Hildesheim: Verlag Franzbecker.

Pehkonen, E., \& Ahtee, M. (2006). Levels of teachers' listening in working with open problems. In Problem solving in mathematics education: proceedings of the ProMath 6 Meeting, 8-11 September 2005 in Debrecen (pp. 63-74).

Pehkonen, E., \& Portaankorva-Koivisto, P. (2015). Teacher Change via participation to a research project. In L. Sumpter (Ed.), Current State of Research on Mathematical Beliefs XX: Proceedings of the MAVI-20 Conference September 29 - October 1, 2014, Falun, Sweden (pp. 163-172). (Kultur och lärande; Nro 2015:04). Falun: Högskolan Dalarna.

Pehkonen, E., Näveri, L., \& Laine, A. (2013). On teaching problem solving in school mathematics. Center for Educational Policy Studies Journal, 3(4), 9-23.

Polly, D., McGee, J. R., Wang, C., Lambert, R. G., Pugalee, D. K., \& Johnson, S. (2013). The association between teachers' beliefs, enacted practices, and student learning in mathematics. Mathematics Educator, 22(2), 11-30. 
Saadati, F., Cerda, G., Giaconi, V., Reyes, C., \& Felmer, P. (2019). Modeling Chilean mathematics teachers' instructional beliefs on problem solving practices. International Journal of Science and Mathematics Education, 17(5), $1009-1029$. https://doi.org/10.1007/s10763-018-9897-8

Santagata, R., \& Yeh, C. (2016). The role of perception, interpretation, and decision making in the development of beginning teachers' competence. ZDM Mathematics Education, 48(1), 153-165. https://doi.org/10.1007/s11858-015-0737-9

Sarama, J., Clements, D. H., Wolfe, C. B., \& Spitler, M. E. (2016). Professional development in early mathematics: effects of an intervention based on learning trajectories on teachers' practices. Nordic Studies in Mathematics Education, 21(4), $29-55$.

Sawada, T. (1997). Developing lesson plans. In J.P Becker, \& S. Shimada (Eds.), The open-ended approach: A new proposal for teaching mathematics (pp. 23-35). Reston, VA: NCTM.

Scheiner, T., Montes, M. A., Godino, J. D., Carrillo, J., \& Pino-Fan, L. R. (2017). What Makes Mathematics Teacher Knowledge Specialized? Offering Alternative Views. International Journal of Science and Mathematics Education, 1-20. https://doi.org/10.1007/s10763-017-9859-6

Schiefele, U., \& Schaffner, E. (2015). Teacher interests, mastery goals, and self-efficacy as predictors of instructional practices and student motivation. Contemporary Educational Psychology, 42, 159-171. https://doi.org/10.1016/j.cedpsych.2015.06.005

Schreier, M. (2012). Qualitative content analysis in practice. Los Angeles: Sage Publications.

Shahbari, J. A. (2017). Mathematical and Pedagogical Knowledge amongst First-and Second-Grade Inservice and Preservice Mathematics Teachers. International Journal for Mathematics Teaching and Learning, 18(1), 45-65.

Shulman, L. S. (1986). Those who understand: Knowledge growth in teaching. Educational Researcher, 15(2), 4-14. https://doi.org/10.3102/0013189x015002004

Shulman. L. (1987). Knowledge and teaching: Foundations of the new reform. Harvard Educational Review, 57, $1-22$. https://doi.org/10.17763/haer.57.1.j463w79r56455411

Siswono, T. Y., Kohar, A. W., Rosyidi, A. H., \& Hartono, S. (2017). Primary school teachers' beliefs and knowledge about mathematical problem-solving and their performance on problem-solving task. World Transactions on Engineering and Technology Education, 15(2), 126-131.

Stahnke, R., Schueler, S., \& Roesken-Winter, B. (2016). Teachers' perception, interpretation, and decision-making: a systematic review of empirical mathematics education research. ZDM, 48(1-2), 1-27. https://doi.org/10.1007/s11858-016-0775-y

Stein, M. K., Engle, R. A., Smith, M. S., \& Hughes, E. K. (2008). Orchestrating productive mathematical discussions: Helping teachers learn to better incorporate student thinking. Mathematical Thinking and Learning, 10, 313-340.

Stipek, D., Givvin, K., Salmon, J., \& MacGyvers, V. (2001). Teachers' beliefs and practices related to mathematics instruction. Teaching and Teacher Education, 17(2), 213-226. https://doi.org/10.1016/S0742-051X(00)00052-4

Swan, M. (2007). The impact of task-based professional development on teachers' practices and beliefs: A design research study. Journal of Mathematics Teacher Education, 10, 217-237. https://doi.org/10.1007/s10857-007-9038-8

Swars, S. L., Smith, S. Z., Smith, M. E., Carothers, J., \& Myers, K. (2018). The preparation experiences of elementary mathematics specialists: examining influences on beliefs, content knowledge, and teaching practices. Journal of Mathematics Teacher Education, 21(2), 123-145. https://doi.org/10.1007/s10857-016-9354-y

Taylor, P. C., Fraser, B. J., \& Fisher, D. L. (1997). Monitoring constructivist classroom learning environments. International Journal of Educational Research, 27(4), 293-302. https://doi.org/10.1016/S0883-0355(97)90011-2

Thompson, A. (1984). The relationship of teachers' conceptions of mathematics teaching to instructional practice. Educational Studies in Mathematics, 15(2), 105-127. https://doi.org/10.1007/BF00305892

Tzur, R. (2008). A researcher perplexity: Why do mathematical tasks undergo metamorphosis in teacher hands? In 0 . Figueras, J. L. Cortina, S. Alatorre, T. Rojano, \& A. Sepulveda (Eds.), Proceedings of the 32nd Conference of the International Group for the Psychology of Mathematics Education (pp. 139-147). Morelia, Mexico: PME.

Viholainen, A., Asikainen, M., \& Hirvonen, P. E. (2014). Mathematics student teachers' epistemological beliefs about the nature of mathematics and the goals of mathematics teaching and learning in the beginning of their studies. Eurasia Journal of Mathematics, Science \& Technology Education, 10(2), 159-171. https://doi.org/10.12973/eurasia.2014.1028a

Wilkins, J. L. M. (2008). The relationship among primary teachers' content knowledge, attitudes, beliefs, and practices. Journal of Mathematics Teacher Education, 11(2), 139-164. https://doi.org/10.1007/s10857-007-9068-2

Wilson, M. S., \& Cooney, T. J. (2002). Mathematics teacher change and development. In G. C. Leder, E. Pehkonen, \& G. Törner (Eds.), Beliefs: A hidden variable in mathematics education (pp. 127-147). Dordrecht: Kluwer. https://doi.org/10.1007/0-306-47958-3_8

Yeo, J. B. (2017). Development of a framework to characterise the openness of mathematical tasks. International Journal of Science and Mathematics Education, 15(1), 175-191. https://doi.org/10.1007/s10763-015-9675-9 